\title{
Pengembangan Motif Batik Sasambo dengan Sistem Lindenmayer
}

\author{
Subaiah Marlina ${ }^{a}$, Qurratul Aini ${ }^{b}$, I Wayan Sudiarta ${ }^{c, *}$ \\ ${ }^{a}$ Program Studi Matematika, FMIPA, Universitas Mataram, Jl Majapahit No 62, Mataram 83125, Indonesia. \\ Email:subaiahmarlinaa@gmail.com \\ b Program Studi Matematika, FMIPA, Universitas Mataram, J1 Majapahit No 62, Mataram 83125, Indonesia. \\ Email:qurratulaini.aini@unram.ac.id \\ c Program Studi Fisika, FMIPA, Universitas Mataram, Jl Majapahit No 62, Mataram 83125, Indonesia. \\ Email:wayan.sudiarta@unram.ac.id
}

\section{A B S T R A C T}

Batik is an Indonesian intangible cultural heritage that needs to be preserved. Indonesia has a variety of batik patterns such as Sasambo (Sasak, Samawa, and Mbojo) batik patterns from West Nusa Tenggara. This study aims to develop Sasambo batik patterns by using the Lindenmayer System (L-System). The Sasambo batik patterns developed in this study are of two types: Lumbung (rice barn) and Kangkung (water spinach) patterns. By applying the L-System, there are three different ways that can be done, namely (1) making the Sasambo batik patterns as axioms, (2) making the batik patterns as generators, and (3) combining the Sasambo patterns with fractals. Based on the new patterns produced using the L-System, the selection of generators should have the initial and final segments which are both in a single line position, so that the original patterns unchanged.

Keywords: L-System, Sasambo Batik Patterns, Fractal Patterns

\section{A B S T R A K}

Batik merupakan warisan budaya Indonesia yang perlu dilestarikan. Indonesia mempunyai beragam motif batik, seperti contohnya di Nusa Tenggara Barat yang memiliki batik Sasak, Samawa, dan Mbojo disingkat Sasambo. Penelitian ini bertujuan untuk mengembangkan motif batik Sasambo dengan sistem Lindenmayer (L-System). Motif batik Sasambo yang digunakan pada penelitian ini adalah motif Lumbung dan motif Kangkung. Ada tiga cara yang dapat dilakukan dengan sistem Lindenmayer yaitu (1) menjadikan motif batik Sasambo sebagai aksioma, (2) menjadikan motif batik sebagai generator dan (3) menggabungkan motif batik Sasambo dengan fraktal. Berdasarkan motif baru yang diperoleh dengan L-System, pemilihan generator sebaiknya memiliki segmen awal dan segmen akhir yang segaris supaya motif aslinya masih terlihat.

* Corresponding author.

Alamat e-mail: subaiahmarlinaa@gmail.com 
Keywords: L-System, Motif Batik Sasambo, Motif Fraktal

Diserahkan: 30-09-2020; Diterima: 23-12-2020;

Doi: https://doi.org/10.29303/emj.v3i2.77

\section{Pendahuluan}

Batik merupakan hal yang tidak dapat dipisahkan dari rakyat Indonesia, terlihat dari kehadiran batik dalam berbagai kegiatan adat, tradisi dan ritual budaya kehidupan masyarakat. Batik telah ditetapkan sebagai warisan kemanusiaan untuk budaya lisan dan nonbendawi milik Indonesia oleh United Nations Educational, Scientific And Cultural Organization (UNESCO) sejak 2 Oktober 2009, dan kemudian setiap 2 Oktober diperingati sebagai hari batik nasional (Parmono, 2013). Batik merupakan kain bergambar yang pembuatannya secara khusus dengan menuliskan atau menerapkan malam (lilin) pada kain itu, kemudian pengolahannya diproses dengan cara tertentu (KBBI, 2020).

Motif batik Indonesia menunjukkan adanya karakteristik self affine yang berarti objek mempunyai detail yang menyerupai dirinya sendiri, karakteristik ini dimiliki oleh fraktal (Lukman, Yun, \& Achmad, 2007). Fraktal berasal dari bahasa latin yaitu fractus yang berarti patah, dapat diartikan juga tidak beraturan (Mandelbrot, 1993). Jadi fraktal digunakan untuk mendefenisikan suatu objek yang tidak dapat didefinisikan pada geometri Euklid karena ketidakteraturannya (Falconer, 2003). Karakteristik ini muncul dikarenakan dalam pembuatan motif batik terdapat proses isen (pengisian motif yang lebih besar terlebih dahulu kemudian diikuti motif yang lebih kecil). Keberadaan karakteristik fraktal dalam batik menunjukkan kompleksitas dalam kesenian tradisional yang muncul karena adanya kewajiban untuk mengikuti aturan pakem yang ada (Lukman, Yun, \& Achmad, 2007).

Penelitian-penelitian yang telah dilakukan menggunakan metode fraktal yaitu membangun motif batik kupu-kupu dengan metode IFS (Yuan, Jian, \& Haisong, 2016), pengulangan motif batik dengan skala yang berbeda dan penggunaan prinsip refleksi (atau pencerminan) seperti yang dilakukan oleh Dewi, Rani, \& Elita (2016). Wulandari, Kosala, \& Ahmad (2017) menggabungkan fraktal kurva naga dengan motif batik daun, sedangkan Kodri \& Titaley (2017) mengembangkan variasi motif batik Minahasa berbasis himpunan Julia.

Salah satu metode untuk menghasilkan objek fraktal adalah sistem Lindenmayer atau L-System. Metode L-System ditemukan oleh Aristid Lindenmayer seorang ilmuwan biologi pada 1986. Lindenmayer awalnya menggunakan L-System untuk mendeskripsikan prilaku dari sel tumbuhan dan untuk memodelkan proses pertumbuhan tumbuhan (Prusinkiewicz \& Lindenmayer, 2004). Pada 1984, A.R Smith menunjukkan bahwa L-System dapat digunakan untuk membuat gambar realistik dan membangun fraktal (Mishra \& Sarojananda, 2007).

Berdasarkan uraian di atas, pada penelitian ini dilakukan pengembangan motif batik Sasambo dengan metode L-System. Motif Sasambo merupakan gabungan motif yang berasal dari tiga etnis di NTB yaitu Sasak, Samawa, Mbojo. Motif ini pertama kali dikembangkan dalam bentuk lukisan di Desa Rambitan, Kecamatan Pujut, Kabupaten Lombok Tengah (Wahdaniah, 2016). Pengembangan motif batik sasambo dengan metode L-System dilakukan agar motif batik Sasambo tidak terlihat monoton dan meningkatkan variasi motif batik Sasambo.

Gambar 1 merupakan contoh motif batik Sasambo yang diproduksi di SMK Negeri 5 Mataram.
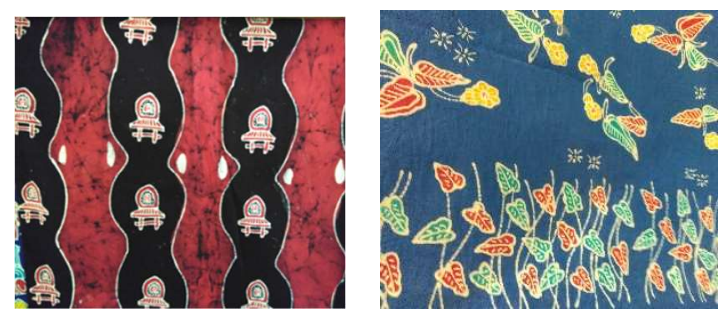

Gambar 1 Batik Sasambo motif Lumbung (kiri) dan motif Kangkung (kanan)

\section{Landasan Teori}

\subsection{Ruang metrik dan fraktal}

Objek fraktal berada dalam ruang metrik, berikut diberikan definisi ruang metrik :

Definisi 2.1 (Bartle, 2000)

Suatu metrik pada himpunan tak kosong $X$ adalah suatu fungsi $d: X \times X \rightarrow \mathbb{R}$, yang memenuhi sifatsifat sebagai berikut:

i. $\quad d(x, y) \geq 0$ untuk setiap $x, y \in X$;

ii. $\quad d(x, y)=0$ jika dan hanya jika $x=y$;

iii. $\quad d(x, y)=d(y, x)$ untuk setiap $x, y \in X$;

iv. $d(x, y) \leq d(x, z)+d(z, y)$ untuk setiap $x, y, z \in X$ 
Selanjutnya, suatu ruang metrik $(X, d)$ adalah himpunan tak kosong $X$ yang dilengkapi dengan suatu metrik $d$ pada $X$.

Sebelum mendefinisikan ruang di mana objek fraktal berada (ruang fraktal), perlu diketahui definisi dari ruang metrik lengkap dan himpunan kompak. Selain itu diberikan juga definisi ruang Hausdorff pada Definisi 2.4 .

Definisi 2.2 (Barnsley, 1993)

Suatu ruang metrik $(X, d)$ dikatakan lengkap jika setiap barisan Cauchy $\left\{x_{n}\right\}$ di dalam $X$ mempunyai limit $x \in X$.

Definisi 2.3 (Barnsley, 1993)

Misalkan himpunan $S \subset X$ adalah sebuah subset dari ruang metrik $(X, d)$. Himpunan $S$ disebut kompak jika untuk setiap barisan tak hingga $\left\{x_{n}\right\}_{n=1}^{\infty}$ di $S$ terdapat subbarisan yang mempunyai limit di $S$.

Definisi 2.4 (Barnsley, 1993)

Misalkan $(X, d)$ adalah suatu ruang metrik lengkap. Koleksi himpunan kompak tak kosong dari $X$ dinotasikan dengan $\mathcal{H}(X)$.

$\mathcal{H}(X)$ disebut dengan ruang Hausdorff.

Berikut diberikan definisi metrik Hausdorff.

Definisi 2.5 (Marwan, 2012)

Misalkan $(X, d)$ adalah suatu ruang metrik lengkap. $\mathcal{H}(X)=\{A \mid A \subset X, A$ kompak, $A \neq \varnothing\} . \quad$ Metrik Hausdorff merupakan suatu fungsi $h: \mathcal{H}(X) \times$ $\mathcal{H}(X) \rightarrow \mathbb{R}$, dengan definisi:

$$
h(A, B)=\max \{d(A, B), d(B, A)\}
$$

$$
\begin{aligned}
& \text { di mana } \\
& \begin{aligned}
& d(A, B)=\max \{d(x, B) \mid x \in A\}, \forall A, B \in \mathcal{H}(X) \\
& d(x, B)=\min \{d(x, y \mid y \in B\}, \forall x \in X \operatorname{dan} B \\
& \in \mathcal{H}(X)
\end{aligned}
\end{aligned}
$$

Himpunan $(\mathcal{H}(X), h(d))$ dinamakan ruang fraktal.

\subsection{Sistem Lindenmayer (L-System)}

Konsep dari L-System adalah penulisan ulang (rewriting) dari untai (string) yang kemudian diterjemahkan menjadi suatu objek. L-System terdiri dari aksioma dan generator. Misalkan untai terdiri dari dua huruf yaitu $\boldsymbol{a}$ dan $\boldsymbol{b}$, setiap huruf mempunyai aturan penulisan ulang atau generator. Aturannya $\boldsymbol{a} \rightarrow$ $\boldsymbol{a} \boldsymbol{b}$ yang berarti huruf $\boldsymbol{a}$ akan diganti dengan string $\boldsymbol{a} \boldsymbol{b}$, dan aturan $\boldsymbol{b} \rightarrow \boldsymbol{a}$ artinya huruf $\boldsymbol{b}$ akan diganti dengan $\boldsymbol{a}$. Proses pembangunan untai diawali dengan sebuah untai yang berbeda yang dinamakan aksioma. Misalkan aksioma-nya $\boldsymbol{a}$, pada langkah pertama aksioma $\boldsymbol{a}$ akan diganti dengan huruf $\boldsymbol{a} \boldsymbol{b}$ sebagaimana aturannya, kemudian langkah pada langkah kedua $\boldsymbol{a}$ diubah menjadi $\boldsymbol{a} \boldsymbol{b}$ dan $\boldsymbol{b}$ berubah menjadi $\boldsymbol{a}$. Untuk lebih jelasnya, perhatikan Gambar 2 (Prusinkiewicz \& Aristid, 2004).

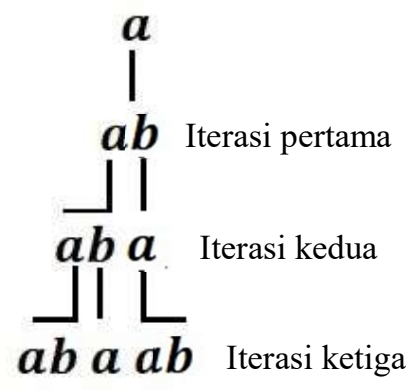

Gambar 2 Contoh iterasi pada metode L-System

Untuk menerjemahkan untai menjadi suatu gambar, maka digunakan interpretasi kura-kura atau turtle graphic. Interpretasi kura-kura ini digambarkan sebagai suatu keadaan awal kura-kura yang dinotasikan sebagai $(x, y, \alpha)$, koordinat cartesius $(x, y)$ menggambarkan posisi kura-kura, dan sudut $\alpha$ disebut heading yaitu arah yang akan dituju oleh kurakura. Ukuran langkah kura-kura dilambangkan $r$ dan $\theta$ menunjukkan peningkatan sudut. Perintah-perintah yang digunakan disimbolkan sebagai berikut (Prusinkiewicz dan Aristid, 2004):

$F$ : Maju ke depan sepanjang $r$. Posisi kura-kura berubah menjadi $\left(x^{\prime}, y^{\prime}, \alpha\right)$, dimana $x^{\prime}=x+$ $r \cos \alpha$ dan $y^{\prime}=y+r \sin \alpha$. Sebuah garis digambar antara titik $(x, y)$ dan $\left(x^{\prime}, y^{\prime}\right)$.

$f$ : Maju ke depan sepanjang $r$ tanpa menggambar sebuah garis.

+ : Belok Kiri sebesar sudut $\theta$. Posisi kura-kura berubah menjadi $(x, y, \alpha+\theta)$.

- : Belok kanan sebesar sudut $\theta$. Posisi kura-kura berubah menjadi $(x, y, \alpha-\theta)$.

\section{Metode Penelitian}

Acuan motif batik yang digunakan diperoleh dari SMK Negeri 5 Mataram, NTB dan hasil penulusuran di internet. Bahasa pemrograman yang digunakan untuk memperoleh motif baru adalah bahasa Python. 
Pada penelitian ini ada tiga cara yang dilakukan dengan L-System yaitu (1) menjadikan motif batik Sasambo sebagai aksioma, (2) menjadikan motif batik sebagai generator dan (3) menggabungkan motif batik Sasambo dengan fraktal.

\section{1 Motif batik sebagai aksioma}

Pembentukan L-System untuk mendapatkan motif baru pada cara pertama ini dilakukan dengan menetapkan motif batik Sasambo sebagai aksioma. Motif batik Sasambo yang dipilih adalah Lumbung. Adapun motif Lumbung pada L-System dapat dilihat pada Gambar 3.

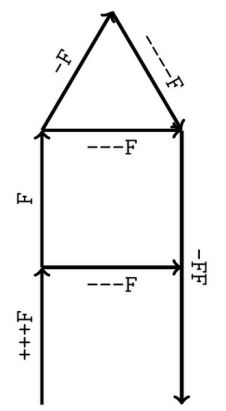

\section{Gambar 3 Aksioma motif Lumbung}

Untaian yang digunakan untuk membentuk motif Lumbung dengan axioma dan sudut $\theta$ yaitu: ++ $+F[---F] F[---F]-F----F-F F$ dan $\theta=30^{\circ}$. Pemilihan generator L-System akan dipilih secara bebas. Namun, gambar yang dihasilkan diharapkan masih menampakkan motif Lumbung.

\section{2 Motif batik sebagai generator}

Generator untuk mendapatkan motif batik yang sesuai dengan motif Lumbung sebaiknya memiliki segmen awal dan segmen akhir yang segaris agar motif yang dihasilkan masih menampakkan motif aslinya. Generator Lumbung yang digunakan diberikan pada Gambar 4 dengan untaian $F \rightarrow F+$ $+F----F----F+++F+++F+++$ $F---F \operatorname{dan} \theta=30^{\circ}$

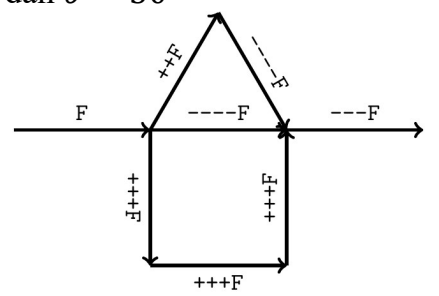

Gambar 4 Generator motif Lumbung

\section{3 Penggabungan motif batik dengan fraktal}

Penggabungan motif batik dan fraktal dilakukan dengan menjadikan fraktal sebagai generator pertama dan motif batik sebagai generator kedua. Dua generator tersebut digunakan untuk membentuk $L$ System. Fraktal yang digunakan pada penelitian ini adalah Levy Dragon dan Snowflake. Adapun motif batik Sasambo yang dipilih sebagai generator pertama adalah motif Kangkung ditunjukkan pada Gambar 5 dan 6 dengan untai sebagai berikut :

Generator motif Kangkung 1 :

$\mathrm{F} \rightarrow \mathrm{F}[++++++\mathrm{F}[\mathrm{F}[++\mathrm{F}] \mathrm{F}[--\mathrm{F}] \mathrm{F}]+++++++\mathrm{F}----\mathrm{F}----$

FF-FF-F-------F-FF-FF----F----F]F dan $\theta=15^{\circ}$

Generator motif Kangkung $2: \mathrm{F} \rightarrow \mathrm{F}[-----$ $\mathrm{F}[\mathrm{F}[++\mathrm{F}] \mathrm{F}[--\mathrm{F}] \mathrm{F}]++++++++\mathrm{F}----\mathrm{F}----\mathrm{FF}-\mathrm{FF}-\mathrm{F}-------\mathrm{F}-$ FF-FF----F----F]F dan $\theta=15^{\circ}$

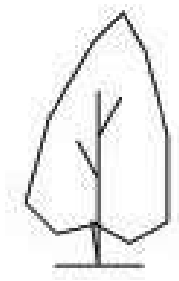

\section{Gambar 5 Motif Kangkung 1}

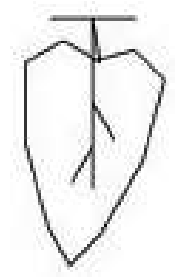

Gambar 6 Motif Kangkung 2

\section{Hasil dan Pembahasan}

Hasil dari pengembangan motif batik Sasambo ditampilkan dalam Tabel 1-3 untuk setiap metode yang digunakan. Motif yang diberikan pada Tabel 1-3 merupakan hasil dari iterasi kedua sampai iterasi keempat. Hasil ini cukup merepresentasikan motif yang didapatkan. Semakin banyak iterasi yang dilakukan akan dihasilkan motif yang semakin detil tetapi secara umum bentuknya hampir sama.

Tabel 1 Hasil Pengembangan dengan Menjadikan Motif Batik Sebagai Aksioma 


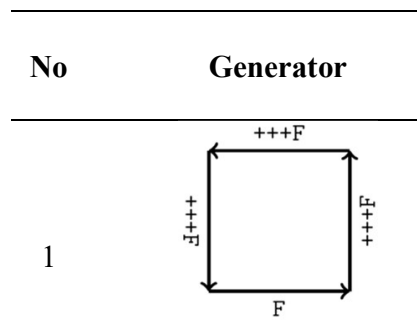

Generator $1: F \rightarrow F+$

$++F+++F+++F$

2

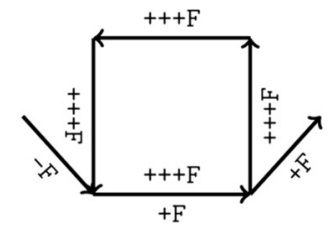

Generator $2: F \rightarrow-F+$ $F+++F+++F+$

$$
++F+++F+F
$$

3

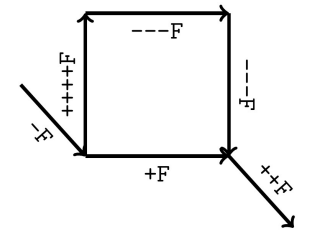

Generator $3: F \rightarrow$

$-F[+F]++++F---$

$F--F++F$

4

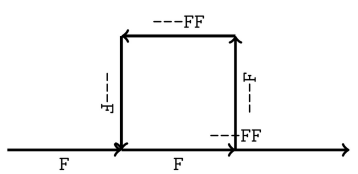

Generator $4: F \rightarrow F F+$

$++F+++F+++$

$$
F+++F F
$$

5

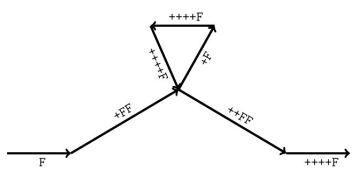

Generator $5: F \rightarrow F+$

$F F+F++++F+++$ $+F+F F+F$

6

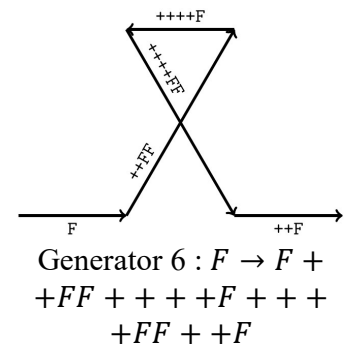

Motif yang

Dihasilkan pada

Iterasi Kedua
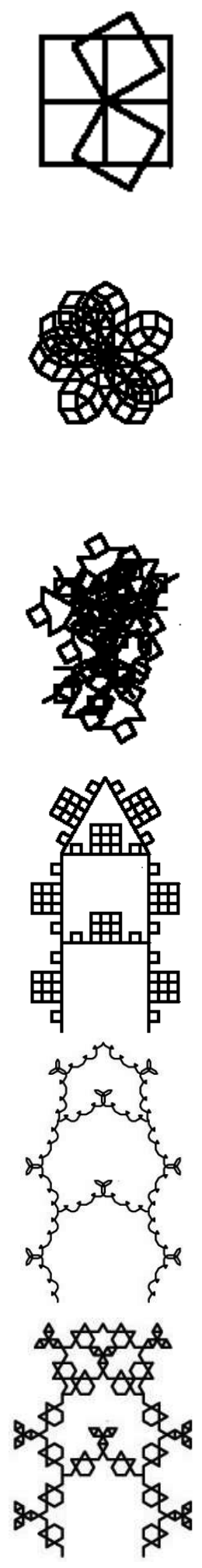

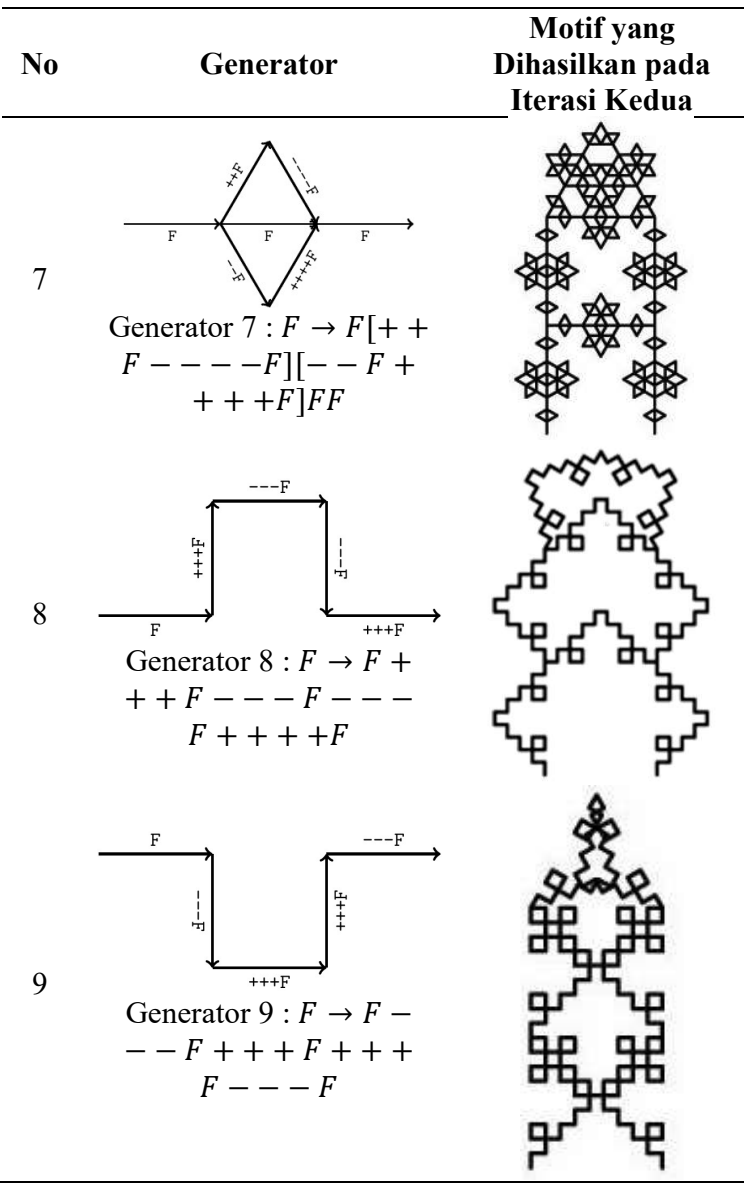

Motif yang dihasilkan oleh generator 1 tidak dapat menunjukkan adanya motif aslinya yaitu motif Lumbung. Pada proses pembuatan motif juga terdapat banyak perulangan segmen dikarenakan segmen awal dan segmen akhir berada pada titik yang sama. Sehingga pada generator selanjutnya segmen awal dan segmen akhir dibuat berbeda. Namun, motif yang dihasilkan oleh generator 2 dan 3 masih belum menunjukkan adanya motif asli.

Generator 4 dan seterusnya dibuat dengan segmen awal dan segmen akhir yang segaris dan menghasilkan motif yang masih menampakkan motif aslinya. Sehingga untuk generator sebaiknya memiliki segmen awal dan segemen akhir yang segaris.

Tabel 2 Hasil Pengembangan dengan Menjadikan Motif Batik Sebagai Generator 


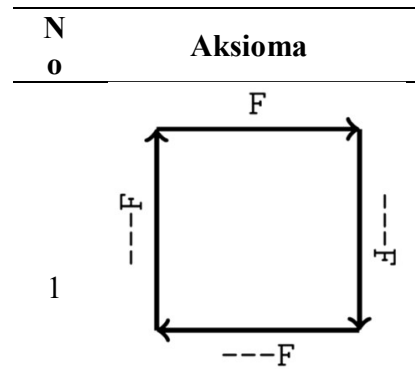

Aksioma $1: \mathrm{F}---$ $\mathrm{F}---\mathrm{F}---\mathrm{F}$

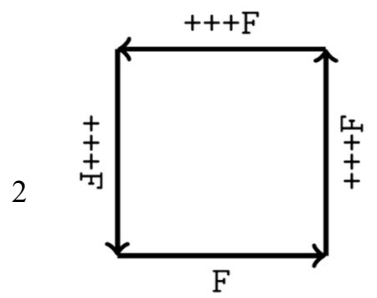

Aksioma $2: \mathrm{F}+++$ $\mathrm{F}+++\mathrm{F}+++\mathrm{F}$

3

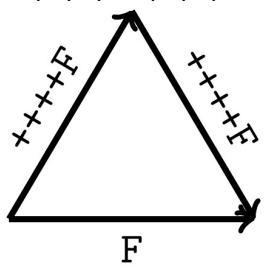

Aksioma $3: \mathrm{F}+++$ $+\mathrm{F}++++\mathrm{F}$

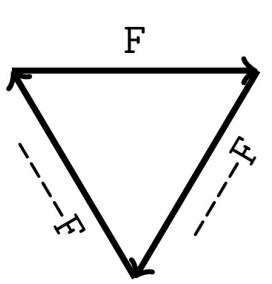

Aksioma $4: \mathrm{F}---$ $-\mathrm{F}---\mathrm{F}$

5
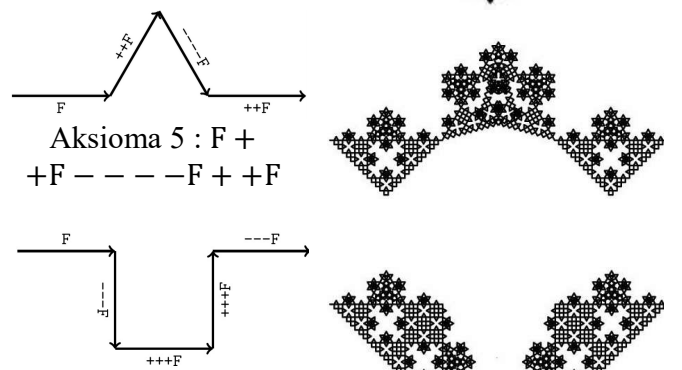

6

$$
\begin{gathered}
\text { Aksioma } 6: \mathrm{F}--- \\
\mathrm{F}+++\mathrm{F}+++ \\
\mathrm{F}---\mathrm{F}
\end{gathered}
$$

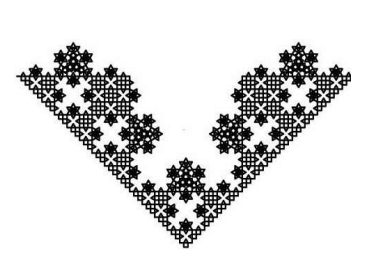

aksioma yang berbeda, perhatikan arah segmen kedua. Pada aksioma 1 segmen kedua berbelok ke kanan sebesar $90^{\circ}$, sedangkan aksioma 2 berbelok ke kiri sebesar $90^{\circ}$. Jadi arah pergerakan setiap segmen akan mempengaruhi gambar yang dihasilkan.

Tabel 3 Hasil Pengembangan Motif Batik Sasambo (Gambar 5 dan 6) dengan Menggabungkan Motif Batik Sasambo dengan Fraktal Levy Dragon dan Snowflake.

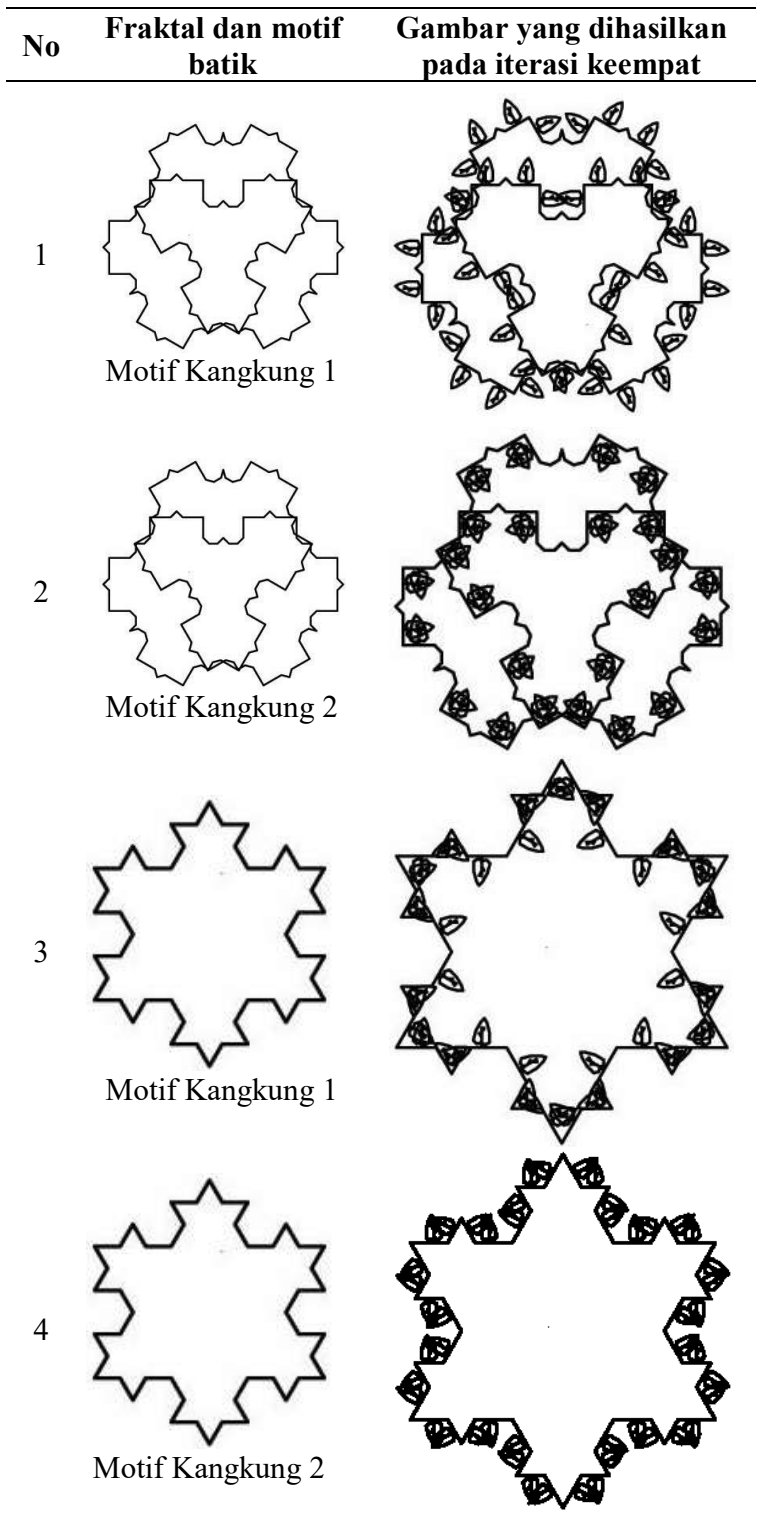

Jika diperhatikan aksioma 1 dan aksioma 2 mempunyai bentuk yang sama, yaitu persegi namun gambar yang dihasilkan berbeda (lihat Tabel 2 baris 1 dan 2). Hal ini dikarenakan proses pembentukan 


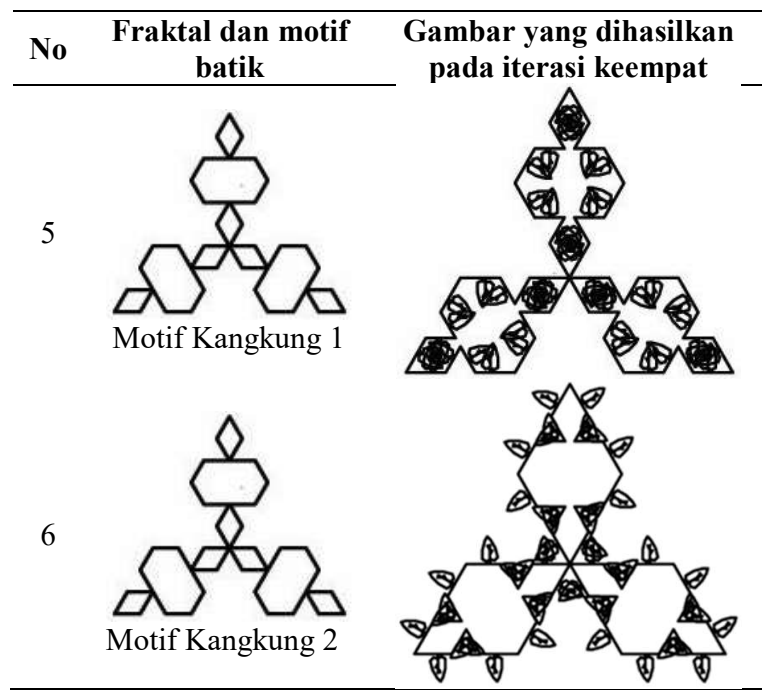

Metode ini tidak menghasilkan model fraktal yang baru, hanya menambahkan motif Kangkung pada segmen fraktal. Perbedaan motif Kangkung 1 dan motif Kangkung 2 terletak pada arah penempatannya.

\section{Kesimpulan}

Berdasarkan penelitian yang telah dilakukan dapat disimpulkan bahwa untuk mendapatkan motif batik baru dengan metode $L$-System dapat dilakukan dengan tiga cara yaitu menjadikan motif batik Sasambo sebagai aksioma, generator, dan menggabungkan motif batik Sasambo dengan fraktal. Adapun untuk mendapatkan motif baru yang motif aslinya masih terlihat maka pemilihan generator sebaiknya memilki segmen awal dan segmen akhir yang segaris.

\section{DAFTAR PUSTAKA}

Badan Pengembangan Bahasa dan Perbukuan, Kementerian Pendidikan dan Kebudayaan Republik Indonesia. (2020, Februari 23). From KBBI Daring: https://kbbi.kemdikbud.go.id/entri/batik

Bartle, R. G., \& Donald, R. S. (2000). Introduction to Real Analysis. New York: John Wiley \& Sons.

Dewi, R. A. M., Rani, R. D., \& Elita I. (2016). Geometri Fraktal Untuk Re-Desain Motif Batik Gajah Oling Banyuwangi. Jurnal Aksioma, vol 5.

Falconer, K. (2003). Fractal Geometry. New York: John Wiley \& Sons.

Kodri, R. F. \& Jullia T. (2017). Variasi Motif Batik Minahasa Berbasis Julia Set. Jurnal Mipa Unsrat.

Lukman, M., Yun, H., \& Achmad, H. D. (2007). Batik Fractal: Traditional Art to Modern Complexity. Procceding Genenrative Art X Milan Italia.
Mandelbrot, B. B. (1993). The Fractal Geometry of Nature. San Diego: Academic Press.

Marwan. (2012). Peran Faktor Penyekala pada Konstruksi Interpolasi Fraktal. Pijar MIPA, vol VI.

Mishra, J. \& Sarojananda M.. (2007). L-System Fractals. Journal Mathematics in Science and Engineering, vol. 209.

Parmono, K. (2013). Nilai Kearifan Lokal dalam Batik Tradisional Kawung. Jurnal Filsafat, vol. 23.

Prusinkiewicz, P. \& Aristid L. (2004). The Algorithm Beauty of Plants. New York: Springer-Verlag.

Ventrella, J. (2012). Brain-Filling Curves, Eyebrain Books.

Wahdaniah, N. (2016). Pembelajaran Motif Batik Sasambo Nusa Tenggara Barat di Kelas Viii/A SMP Negeri 4 Sleman Yogyakarta. Skripsi Jurusan Pendidikan Seni Rupa Fakultas Bahasa dan Seni Universitas Negeri Yogyakarta.

Wulandari, E. Y., Kosala, D. P., \& Ahmad, K. (2017). Pengembangan Desain Batik Labako dengan Menggabungkan Geometri Graktal Kurva Naga dan Corak Daun Tembakau. Ilmu Dasar, Vol 18.

Yuan, Q., Jian, L., \& Haisong, H. (2016). AutoGeneration Method of Butterfly Pattern of Batik Based on Fractal Geometry. International Journal of Signal Processing, Image Processing and Pattern Recognition, vol. 9, no. 4. 